\title{
Risk factors for multidrug-resistant pathogens in bronchiectasis exacerbations
}

\author{
Rosario Menéndez ${ }^{1,5^{*}}$ (D), Raúl Méndez ${ }^{1}$, Eva Polverino ${ }^{2,5}$, Edmundo Rosales-Mayor ${ }^{2}$, Isabel Amara-Elori ${ }^{1}$, \\ Soledad Reyes ${ }^{1}$, José Miguel Sahuquillo-Arce ${ }^{3}$, Laia Fernández-Barat ${ }^{4,5}$, Victoria Alcaraz ${ }^{4,5}$ and Antoni Torres ${ }^{4,5}$
}

\begin{abstract}
Background: Non-cystic fibrosis bronchiectasis is a chronic structural lung condition that courses with recurrent infectious exacerbations that lead to frequent antibiotic treatment making this population more susceptible to acquire pathogens with antibiotic resistance. We aimed to investigate risk factors associated with isolation of multidrug-resistant pathogens in bronchiectasis exacerbations.
\end{abstract}

Methods: A prospective observational study was conducted in two tertiary-care hospitals, enrolling patients when first exacerbation appeared. Multidrug-resistance was determined according to European Centre of Diseases Prevention and Control classification.

Results: Two hundred thirty three exacerbations were included and microorganisms were isolated in 159 episodes. Multidrug-resistant pathogens were found in 20.1\% episodes: Pseudomonas aeruginosa (48.5\%), methicillin-resistant Staphylococcus aureus (18.2\%) and Extended spectrum betalactamase + Enterobacteriaceae (6.1\%), and they were more frequent in exacerbations requiring hospitalization ( $24.5 \%$ vs. $10.2 \%, p: 0.016)$. Three independent multidrugresistant risk factors were found: chronic renal disease (Odds ratio (OR), 7.60, 95\% Cl 1.92-30.09), hospitalization in the previous year $(\mathrm{OR}, 3.8895 \% \mathrm{Cl} 1.37-11.02)$ and prior multidrug-resistant isolation $(\mathrm{OR}, 5.58,95 \% \mathrm{Cl} 2.02-15.46)$. The proportion of multidrug-resistant in the 233 exacerbations was as follows: $3.9 \%$ in patients without risk factors, $12.6 \%$ in those with 1 factor and $53.6 \%$ if $\geq 2$ risk factors.

Conclusions: Hospitalization in the previous year, chronic renal disease, and prior multidrug-resistant isolation are risk factors for identification multidrug-resistant pathogens in exacerbations. This information may assist clinicians in choosing empirical antibiotics in daily clinical practice.

Keywords: Multidrug-resistant, Pseudomonas, Hospitalization

\section{Background}

Multidrug-resistant (MDR) pathogens are a worldwide health threat with clinical negative consequences if inadequately recognized and treated. Non-cystic fibrosis bronchiectasis (BE) is a chronic structural lung condition that facilitates chronic colonization by microorganisms and courses with frequent exacerbations and recurrent infections. [1, 2] This means that patients receive numerous courses with broad-spectrum antibiotics, making them more likely to acquire MDR pathogens.

\footnotetext{
* Correspondence: rosmenend@gmail.com

'Pneumology Department, Hospital Universitario y Politécnico La Fe / Instituto de Investigación Sanitaria (IIS) La Fe, Universidad de Valencia, Valencia, Spain ${ }^{5}$ Centro de Investigación Biomédica En Red-Enfermedades Respiratorias (CIBERES, CB06/06/0028), Madrid, Spain

Full list of author information is available at the end of the article
}

The main pathogens involved in chronic colonization and acute exacerbations are Haemophilus influenzae, Streptococcus pneumoniae, Pseudomonas aeruginosa, and, to a lesser extent, Enterobacteriaceae. The incidence and spread of MDR microorganisms among $\mathrm{BE}$ patients is worrisome because the antibiotic arsenal is scarce and the most threatening potential MDR pathogens in respiratory patients include $P$. aeruginosa and extended-spectrum betalactamase (ESBL) Enterobacteriaceae. These pathogens are difficult to treat because they require different antibiotic regimens to those usually recommended in guidelines.

To our knowledge, no prospective studies have been aimed at identifying independent risk factors for MDR pathogens in BE exacerbations. [3, 4] We hypothesized 
that MDR exacerbations depend on patient characteristics, including usual treatments and prior health contacts, and that knowledge of these factors may be useful for reducing inappropriate antibiotic treatment.

The aim of our study was to investigate risk factors associated with isolation of multi-drug resistant microorganisms in bronchiectasis exacerbations and their clinical impact on outcome.

\section{Methods}

We conducted a prospective and observational study of adult patients with bronchiectasis attended in the specialized clinic of two tertiary care university hospitals during the period 2011-2015. In our specific specialized clinic, patients are referred from primary care, other hospitals, other specialties or any other medical facilities. We confirmed the diagnosis of bronchiectasis by computerized tomography scan of lungs along with compatible symptoms and aetiology of bronchiectasis had been investigated according to Spanish guidelines [5] previous to study recruitment. Local committees approved the study and patients gave written informed consent (Biomedical research ethics committee Hospital La Fe 2011/0342).

Patients were enrolled in the study when they presented the first exacerbation (after signing the informed consent) and required new antibiotic treatment or hospital admission and no subsequent exacerbations for every patient were included. Exclusion criteria were: a) severe immunosuppression, such as in solid-organ or bone-marrow transplantation or HIV/AIDS, or receiving chemotherapy or other immunosuppressive drugs ( $\geq 20 \mathrm{mg}$ prednisoneequivalent per day for 2 weeks or more); b) active tuberculosis; c) cystic fibrosis (CF); d) pulmonary interstitial disease and e) hospitalization in the preceding 21 days.

\section{Study protocol}

Data collected were demographic, diagnosis of $\mathrm{BE}$, smoking, alcohol abuse and flu vaccine status. Comorbidities were also recorded (diabetes, COPD, asthma, heart disease, prior tuberculosis, renal, liver and cerebrovascular diseases) and age-adjusted Charlson score. [6] Data related to prior microorganisms isolation, number of exacerbations in the previous year, bronchiectasis severity scores (BSI, FACED) $[7,8]$ were also recorded. Chronic and concomitant medication included bronchodilators, corticosteroids, theophylline, inhaled/nebulized antibiotics, proton pump inhibitors, long-term oxygen therapy and mucolytic drugs. A history of prior exacerbations and hospitalization during the previous year were also detailed.

\section{Exacerbation definition and follow-up}

The definition of exacerbation according to Spanish guidelines [5] was as follows: acute change in sputum characteristics (increased volume, change of viscosity, purulence) with or without increased dyspnea after ruling out any other causes along with the requirement of a new antibiotic treatment prescribed in our specific clinic and / or unscheduled admission to hospital. We included also exacerbations with new chest $\mathrm{x}$-ray infiltrates diagnosed as pneumonia. The attending physician made the decision to admit to hospital. During the exacerbation episode, data collected were change of initial antibiotic, complications, invasive and noninvasive mechanical ventilation, and mortality. Length of hospital stay was recorded in hospitalized patients and new exacerbations at 1 year of follow-up. Inappropriate antibiotic treatment was considered when pathogens were not susceptible to the prescribed antibiotic with respect to in vitro susceptibility testing. Patients were followed up for visits in the specialized clinic at 30 days, 90 days and 1 year after discharge.

\section{Microbiological evaluation and diagnosis}

The microbiological diagnosis was performed with the following tests: sputum (208 patients), urine antigen test for S. pneumoniae (126) and L. pneumophila (128), two blood samples (87) and nasopharyngeal swabs (125) (for influenza $A$ and $B$, parainfluenzae, syncytial respiratory virus, adenovirus). Sputum and bronchoalveolar lavage (11) were processed for Gram and Ziehl-Neelsen stains and for cultures of bacterial, fungal and mycobacterial pathogens. Sputum samples were considered acceptable if there were more than 25 leukocytes and fewer than 10 squamous cells per low-power microscope field. Invasive samples were obtained if requested by the attending physician. Microorganism identification was consider positive as in previous publications. [9] Briefly, bacterial identification was achieved by means of the MALDI-TOF MS (Biomerieux, Marcy l'Etoile, France). Antimicrobial susceptibility was tested by the Kirby-Bauer disk diffusion technique on Muller-Hinton or sheep blood agar, depending on the microorganism growth requirements; E-test and in-house PCR were used to assess unexpected resistance patterns.

Concept of Multidrug resistant pathogens (MDR) [10] MDR pathogens were classified according to European Centre of Diseases Prevention and Control: P. aeruginosa was considered MDR if non susceptible to at least 1 agent in 3 or more antimicrobial categories; MRSA was defined when $S$ aureus was resistant to oxacillin corresponding to a minimum inhibitory concentration (MIC) of $\geq 4 \mathrm{mcg} / \mathrm{mL}$. Enterobacteriaceae was defined as ESBL+ when they presented resistance to most $\beta$-lactam antibiotics, including penicillin, cephalosporins and aztreonam.

\section{Statistical analysis Univariate analysis}

Statistical analyses were performed using the SPSS software program 20.0. Qualitative variables were compared 
using the $x^{2}$ test. Quantitative variables were analyzed using the ANOVA test or the Kruskal-Wallis test. Values of $\mathrm{p} \leq 0.05$ were considered statistically significant. Length of stay was dichotomized as short ( $\leq 7$ days) or long stay. FACED and BSI were dichotomized as severe ( $\geq 5$ and $\geq 9$ points respectively) and not severe.

\section{Multivariate Analysis}

Logistic regression analyses were performed to predict MDR pathogens as the dependent variable. Independent variables included were those found in the univariate analysis with $p<0.1$. Variables that were highly correlated were excluded from the analysis. The subset of patients with non-MDR pathogens was used as the reference group. A second logistic regression analysis was also performed using as the reference group patients with non-MDR pathogens and patients without etiological diagnosis. The Hosmer and Lemeshow goodness-of-fit test was used to evaluate the adequacy of the models. [11] The areas under the receiveroperator characteristic (ROC) curves were also calculated.

\section{Results}

\section{Patient characteristics}

We recruited 233 patients with one exacerbation and microbial isolation was found in 159 of them (Fig. 1). Characteristics of patients, BE diagnosis, previous microorganisms isolations, number of exacerbations, number of prior antibiotic treatments, usual concomitant medications and severity scores are described in Table 1.

\section{Microbiological results}

The most frequent pathogens found during exacerbation are described in Table 2. MDR pathogens isolated during an exacerbation were found in 32 out of 241 microorganism, representing $13.2 \%$ of all microorganisms isolated: 16 (50\%) MDR Pseudomonas aeruginosa, 6 (18.7\%) methicillin-resistant Staphylococcus aureus, 2 (6.2\%) extended-spectrum beta-lactamase-producing Enterobacteriaceae (Proteus mirabilis and Serratia marcescens) and 8 other bacteria (2 Achromobacter xylosoxidans, 2 Stenotrophomonas maltophilia, 1 Brevundimonas diminuta, 1 MDR Escherichia coli not ESBL, 1 Haemophilus influenzae ESBL and 1 MDR Mycobacterium abscessus).

\section{Follow-up and outcome}

Patients who required admission were more likely to grow MDR organisms than those who did not require admission (27/153 vs 5/80, p:0.016)(Fig. 1). Antibiotics initially prescribed for the exacerbation were changed in $37 / 159$ patients, this occurred more frequently in those with MDR pathogens without reaching statistical significance (31.2\% vs. $21.3 \%$, p:0.23). In Table 3, there is depicted the outcome of exacerbations with regard to isolation MDR pathogens and patients without isolation are not included.

\section{Risk factors for MDR pathogen exacerbations Univariate results}

Characteristics of patients, comorbid conditions, usual treatments, and scores regarding the presence or absence of MDR are shown in Table 1. Exacerbations were recorded and 153 of these patients were hospital admitted.

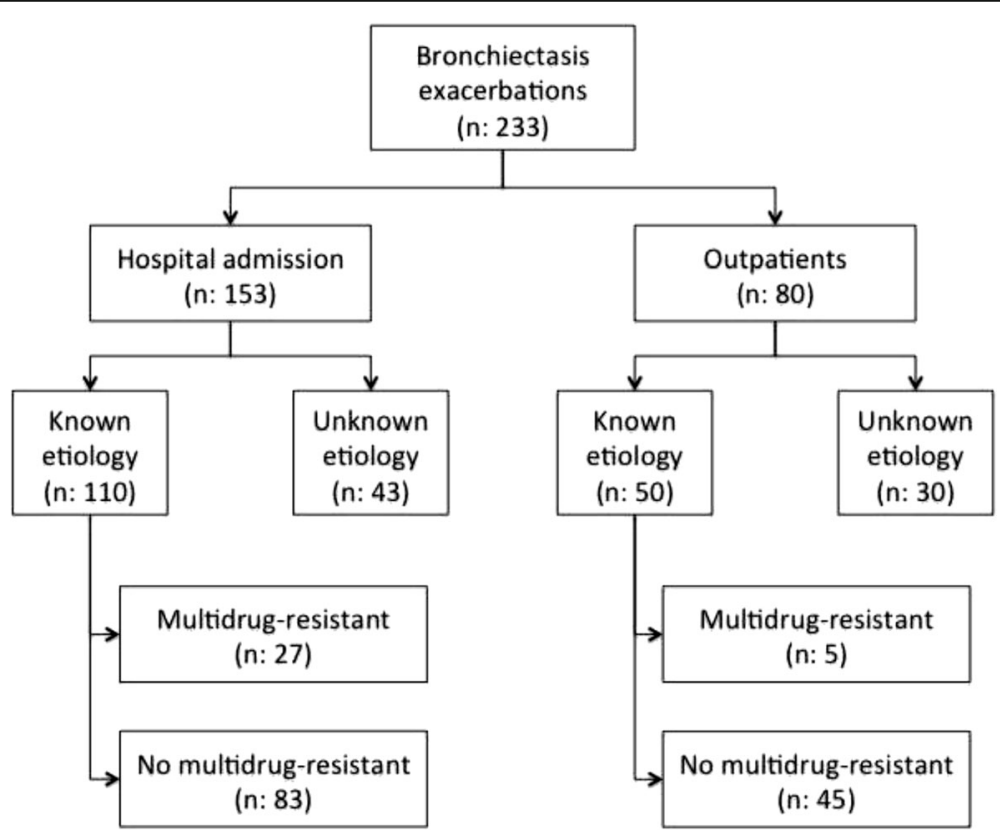

Fig. 1 Flowchart 
Table 1 Characteristics of patients according to isolation of multidrug-resistant microorganism in exacerbation

\begin{tabular}{|c|c|c|c|c|}
\hline \multirow[t]{2}{*}{ Characteristics } & & \multicolumn{3}{|c|}{ Multidrug-Resistant Microorganisms Isolated } \\
\hline & & \multirow{2}{*}{$\begin{array}{l}\text { No } \\
127(79.9)\end{array}$} & \multirow{2}{*}{$\begin{array}{l}\text { Yes } \\
32(20.1)\end{array}$} & \multirow[t]{2}{*}{$p^{9}$} \\
\hline Total No. & & & & \\
\hline \multirow[t]{6}{*}{ Demographic data } & Age & $70(62-77)$ & $75(68-79.5)$ & 0.056 \\
\hline & $>65$ years & $82(64.6)$ & $25(78.1)$ & 0.159 \\
\hline & Male & $50(39.4)$ & $18(56.2)$ & 0.085 \\
\hline & Smoker or former smoker & $58(45.7)$ & $18(56.2)$ & 0.284 \\
\hline & Alcohol abuse $^{a}$ & $6(4.7)$ & $2(6.2)$ & 0.724 \\
\hline & Flu vaccine & $89(70.1)$ & $18(56.2)$ & 0.136 \\
\hline \multirow[t]{15}{*}{ Comorbid condition } & Arterial hypertension & $54(42.5)$ & $20(62.5)$ & 0.043 \\
\hline & Diabetes mellitus & $20(15.7)$ & $7(21.9)$ & 0.409 \\
\hline & Myocardial infarction & $11(8.7)$ & $1(3.1)$ & 0.289 \\
\hline & Congestive heart failure & $14(11)$ & $8(25)$ & 0.041 \\
\hline & Cerebrovascular disease & $3(2.4)$ & $1(3.1)$ & 0.805 \\
\hline & $\mathrm{COPD}^{\mathrm{b}}$ & $32(25.2)$ & $14(43.8)$ & 0.039 \\
\hline & Asthma & $12(9.4)$ & $3(9.4)$ & 0.990 \\
\hline & Previous pulmonary tuberculosis & $11(8.7)$ & $4(12.5)$ & 0.507 \\
\hline & Renal disease & $6(4.7)$ & $7(21.9)$ & 0.002 \\
\hline & Liver disease & $8(6.3)$ & $2(6.2)$ & 0.984 \\
\hline & Age-adjusted Charlson $>5$ & $46(36.2)$ & $17(53.1)$ & 0.081 \\
\hline & Cystic bronchiectasis & $7(5.5)$ & $4(12.9)$ & 0.147 \\
\hline & Chronic Pseudomonas aeruginosa infection & $58(45.7)$ & $18(56.2)$ & 0.284 \\
\hline & Chronic infection by other microorganism & $32(25.2)$ & $9(29)$ & 0.662 \\
\hline & Prior isolation of $\mathrm{MDR}^{\mathrm{C}}$ microorganism & $11(8.7)$ & $13(40.6)$ & 0.000 \\
\hline \multirow[t]{11}{*}{ Treatment } & Long-acting B-agonist & $99(78)$ & $28(87.5)$ & 0.229 \\
\hline & Long-acting Anticholinergic & $72(56.7)$ & $19(59.4)$ & 0.784 \\
\hline & Theophylline & $5(3.9)$ & $3(9.4)$ & 0.208 \\
\hline & Inhaled corticosteroids & $96(75.6)$ & $26(81.2)$ & 0.498 \\
\hline & Long term oral corticosteroids $^{d}$ & $11(8.7)$ & $2(6.2)$ & 0.656 \\
\hline & Long term oral antibiotics & $15(11.8)$ & $4(12.5)$ & 0.914 \\
\hline & Inhaled/Nebulized antibiotic & $25(19.7)$ & $11(34.4)$ & 0.076 \\
\hline & Mucolytics & $43(33.9)$ & $9(28.1)$ & 0.537 \\
\hline & Proton pump inhibitor & $65(51.2)$ & $20(62.5)$ & 0.251 \\
\hline & Chronic oxygen therapy & $14(11)$ & $9(28.1)$ & 0.014 \\
\hline & Regular chest physiotherapy & $43(33.9)$ & $10(31.2)$ & 0.780 \\
\hline \multirow[t]{5}{*}{ History of exacerbations } & Hospitalization last year & $62(48.8)$ & $26(81.2)$ & 0.001 \\
\hline & Previous history of pneumonia & $67(52.8)$ & $14(43.8)$ & 0.362 \\
\hline & Exacerbation last year & $98(77.2)$ & $28(87.5)$ & 0.198 \\
\hline & $\mathrm{N}^{\circ}$ exacerbations last year & $1(1-2)$ & $2(1-3)$ & 0.108 \\
\hline & Courses of antibiotic last year & $1(1-3)$ & $2(1-3)$ & 0.366 \\
\hline \multirow[t]{2}{*}{ Prognostic scales } & Severe FACED & $16(12.6)$ & $9(28.1)$ & 0.031 \\
\hline & Severe BSI ${ }^{f}$ & $74(58.3)$ & $26(81.2)$ & 0.016 \\
\hline
\end{tabular}

Data are presented as $\mathrm{n}(\%)$ or median (interquartile range)

alcohol abuse: more than $80 \mathrm{~g} /$ day

${ }^{\mathrm{b} C O P D}$ : chronic obstructive pulmonary disease

${ }^{c} M D R$ : multidrug-resistant

${ }^{\mathrm{d} L o n g}$ term oral steroids: less than $20 \mathrm{mg} /$ day prednisone or equivalent

eFACED: FEV1, age, colonization, extension, dyspnea

$\mathrm{f}_{\mathrm{BSI}}$ : bronchiectasis severity index

${ }^{9} p$ value: the $x^{2}$ test was performed for categorical data and the Mann-Whitney $\mathrm{U}$ test was performed for continuous data 
Table 2 Microorganisms isolated in exacerbations

\begin{tabular}{|c|c|}
\hline Microorganism Isolated & Total No. 241 (100) \\
\hline Pseudomonas aeruginosa & $51(21.16)$ \\
\hline${ }^{\mathrm{a} M D R}$ Pseudomonas aeruginosa & $16(6.64)$ \\
\hline Methicillin susceptible Staphylococcus aureus & $11(4.56)$ \\
\hline Methicillin resistant Staphylococcus aureus & $6(2.49)$ \\
\hline Acinetobacter sp & $3(1.24)$ \\
\hline Moraxella catarrhalis & $7(2.9)$ \\
\hline Stenotrophomonas maltophilia & $4(1.66)$ \\
\hline Enterobacteriaceae & $12(4.98)$ \\
\hline Escherichia coli & $5(2.07)$ \\
\hline Proteus spp & $3(1.24)$ \\
\hline Klebsiella pneumonia & $3(1.24)$ \\
\hline Serratia spp & $1(0.41)$ \\
\hline Haemophilus influenzae & $27(11.2)$ \\
\hline Streptococcus pneumoniae & $25(10.37)$ \\
\hline Achromobacter xylosoxidans & $5(2.07)$ \\
\hline Mycoplasma pneumoniae & $6(2.49)$ \\
\hline Chlamydia pneumoniae & $1(0.41)$ \\
\hline Atypical mycobacteria & $4(1.66)$ \\
\hline Aspergillus spp & $12(4.98)$ \\
\hline Candida spp & $15(6.22)$ \\
\hline Virus & $25(10.37)$ \\
\hline Coronavirus & $1(0.41)$ \\
\hline Metapneumovirus & $4(1.65)$ \\
\hline Rhinovirus & $10(4.14)$ \\
\hline Influenza A & $3(1.24)$ \\
\hline Influenza B & $2(0.82)$ \\
\hline Parainfluenza 3 & $2(0.82)$ \\
\hline Respiratory Syncytial virus & $3(1.24)$ \\
\hline Others & $11(4.56)$ \\
\hline
\end{tabular}

aMD: Multidrug-resistant
MDR pathogens were more frequently encountered in patients with more chronic conditions and in those with higher FACED and BSI scores. No differences were found concerning usual prior treatments. Patients with prior hospitalization showed a significantly more frequent incidence of MDR.

\section{Multivariate results}

Three independent predictors to MDR exacerbations were identified. The area under the ROC curve for the model was 0.767 (95\% CI, 0.669-0.865) (Table 4). In the second model using as a reference group patients with non-MDR pathogens and those without etiological diagnosis, these risk factors remained independently associated with MDR bacteria.

\section{Probability of MDR and number of risk factors}

The presence of MDR in exacerbations with regard to the number of recognized risk factors found is shown in Fig. 2. No risk factors were identified in 102 patients and the probability of MDR in these patients was $3.9 \%$. This probability increases to $12.6 \%$ when there is 1 risk factor and to $53.6 \%$ if 2 or more risk factors are present in total cohort.

\section{Discussion}

The most notable findings of our study are the following: 1 . MDR pathogens are frequently (20.1\%) isolated in $\mathrm{BE}$ exacerbations, with a higher proportion among hospitalized patients (24.5\%); 2 . The principal MDR microorganisms were Pseudomonas (46\%), MRSA and ESBL+ Enterobacteriaceae; 3. Independent MDR risk factors were prior MDR isolation, hospitalization in the previous year and chronic renal disease.

Due to the structural changes in permanently dilated airways, bronchiectasis courses with recurrent infections and exacerbations. Pathogens involved depend on several aspects: lung function, advanced phase of the disease and patient comorbidities. [1, 2, 12] However, little is known regarding frequency and factors associated with isolation MDR at exacerbations [13].

We found that in 20\% of exacerbations MDR pathogens were isolated and the most frequent were Pseudomonas, MRSA and ESBL+ Enterobacteriaceae. We evaluated resistance using conventional methods usually performed in daily routine and we don't perform automated methods or clonal analysis of resistance. [14] The percentage and spectrum of MDR is more similar to nosocomial than to community-acquired infections, in line with the current approach to those problematic pathogens based on host characteristics and prior treatments, [3, 13, 14] and slightly higher than that reported by McDonnell et al. [15] In fact, MDR exacerbations occurred in elderly patients with a higher proportion of comorbid conditions, indicating associations with more debilitating diseases, requiring multidrug-resistant pathogens or not in the exacerbation

\begin{tabular}{llll}
\hline Follow-up & No MDR & MDR $^{a}$ & $p^{b}$ \\
\hline Complications & $18(14.9)$ & $4(12.5)$ & 0.733 \\
Change in the initial treatment & $27(21.3)$ & $10(31.2)$ & 0.232 \\
Adequate initial treatment & $108(85)$ & $24(75)$ & 0.176 \\
Length of stay & $8(6-11)$ & $8(6-14)$ & 0.925 \\
Exacerbation year & $69(56.1)$ & $25(62.5)$ & 0.514
\end{tabular}

Data are presented as $\mathrm{n}(\%)$ or median (interquartile range)

${ }^{a}$ MDR: Multidrug-resistant

${ }^{b} p$ value: the $x^{2}$ test was performed for categorical data and the

Mann-Whitney $U$ test was performed for continuous data 
Table 4 Multivariate analysis to predict Multidrug-resistant pathogens

\begin{tabular}{llll}
\hline & \multicolumn{2}{l}{ Multidrug-Resistant Microorganisms } \\
\cline { 2 - 4 } & $\mathrm{OR}^{\mathrm{a}}$ & $95 \% \mathrm{Cl}^{\mathrm{b}}$ & $0.97-1.09$ \\
Age & 1.03 & $0.25-2.41$ & 0.393 \\
Male & 0.77 & $0.27-2.62$ & 0.656 \\
Arterial hypertension & 0.83 & $0.40-6.45$ & 0.756 \\
Congestive heart failure & 1.60 & $0.45-5.03$ & 0.511 \\
COPD & 1.51 & $1.92-30.09$ & 0.500 \\
Renal disease & 7.60 & $0.19-2.16$ & 0.004 \\
$\quad$ Age-adjusted Charlson $>5$ & 0.64 & $0.11-1.55$ & 0.469 \\
Chronic Pseudomonas aeruginosa infection & 0.41 & $2.02-15.46$ & 0.189 \\
Prior multidrug-resistant microorganism isolation & 5.58 & $0.57-6.47$ & 0.001 \\
Inhaled/Nebulized antibiotic & 1.93 & $0.57-6.32$ & 0.288 \\
Chronic oxygen therapy & 1.90 & $1.37-11.02$ & 0.297 \\
Hospitalization last year & 3.88 & $0.22-2.29$ & 0.011 \\
$\quad$ Severe FACED & 0.72 & $0.42-5.95$ & 0.573 \\
Severe BSI & 1.58 & & 0.501 \\
\hline
\end{tabular}

${ }^{a} O R$ : Odds ratio

${ }^{\mathrm{b}} \mathrm{Cl}$ : Confidence interval

more contacts with health resources. Our results showed that the use of prior inhaled antibiotics and long-term oxygen therapy was greater in patients with MDR pathogens. Interestingly, no differences were found with regard to the use of bronchodilators or inhaled corticosteroids. Metersky et al. [16] have reported that, in health-care associated pneumonia, inhaled corticosteroids were associated with Pseudomonas etiology, although they found no association with resistance.
The spectrum of microorganisms identified, [17] whether treated as outpatients or in hospital, was similar except for the fact that MDR was barely encountered in outpatients. [18] The fact that MDR exacerbations were more frequently admitted is clinically relevant because exacerbations that require hospitalization have been reported to be associated with an increase in 1-year mortality. [19]

In our study, we found three independent MDR risk factors: renal disease, prior MDR isolation and hospitalization

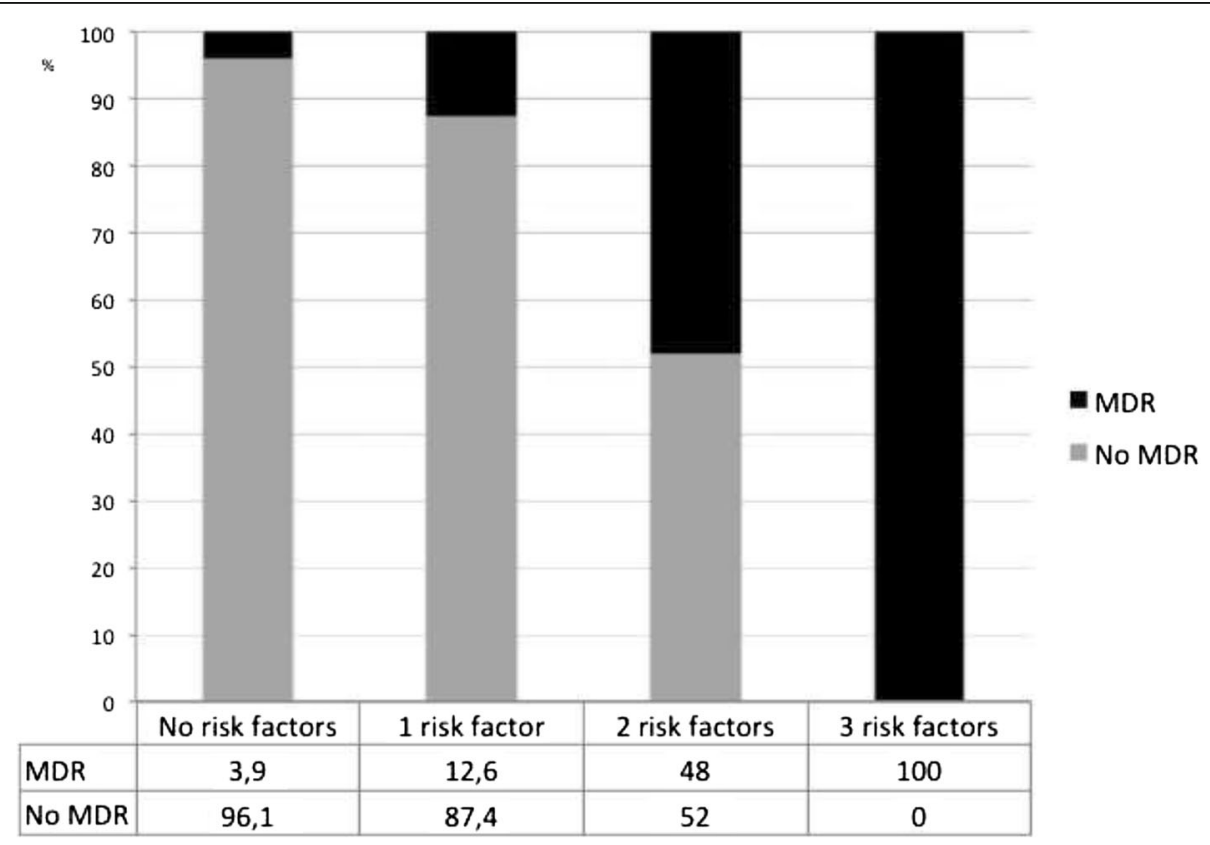

Fig. 2 Number of independent MDR risk factors and percentage of MDR etiology 
in the previous year. Chronic renal disease is a recognized MDR risk factor, as reported in pneumonia studies. [3] Shindo et al., [20] identified 6 independent MDR risk factors, regardless of whether the patient has health-care associated or community-acquired pneumonia, suggesting that risk factors relied more on host factors than on the setting of infection. Prior hospitalization is a fairly widely recognized independent MDR risk factor and specifically for MRSA, [21] and for Enterobacteriacea mainly related to exposure to III/IV generation of cephalosporins or broadspectrum penicillins. [22]

Prior MDR isolation was independently associated with a higher risk of MDR exacerbation. In our cohort, approximately $50 \%$ of patients had chronic Pseudomonas infection, [23] reflecting the most severe patients seen in a specific BE clinic. Prior MDR colonization is a recognized risk factor for MRSA [24, 25] and for Pseudomonas [26] in COPD patients. We found that $40 \%$ of patients with MDR exacerbations had prior isolation with the same microorganism.

The proportion of MDR exacerbations was higher among those patients with higher FACED and BSI scores, as expected in more advanced BE disease, with more proportion of exacerbations and hospitalizations. Almost 80\% of MDR exacerbations occurred in patients with higher punctuations in prognostic scales such as FACED or BSI whereas MDR in mild scales were lower $6.2 \%$ and $40.6 \%$ respectively. However, after entering in the model other independent factors, these scales are not remaining independently associated with multi-drug resistance.

With regard antimicrobial susceptibility, MDR exacerbations received less appropriate treatment than nonMDR, thus also requiring more changes in antibiotic regimens although without statistical differences. In fact, the choice of initial treatment was microbiological suitable in $75 \%$ of cases, probably because physicians took into consideration prior MDR colonization, [27] a policy that is supported by our findings. Currently, factors considered in the antibiotic selection include extent of the disease, severity, local resistance patterns, and prior culture results. [28] A practical conclusion is that extended-spectrum antibiotics against MDR could be withdrawn in patients with no risk factors and indicated if 2 or more risk factors are present. Where 1 risk factor is present, an extendedspectrum antibiotic may be indicated until MDR pathogens have been ruled out; a microbiological work-up should therefore be implemented. [29] Nevertheless, these recommendations need to be validated in different populations or BE subsets [30] and knowledge of local resistance rates and colonization rates should be considered. This policy may contribute to containing broad-spectrum coverage for MDR in unnecessary episodes and this strategy may contribute to curbing the future emergence of resistant microorganisms in this population.
Patients with MDR exacerbations required more hospitalizations and greater use of antibiotics although without longer hospital stay. In general, MDR infections have been associated with a higher number of days of hospitalization, [31] with higher antibiotic requirements, more hospitalization, [32] more use of health resources, with the attendant higher costs, and may eventually have a negative impact on prognosis. [33] Nevertheless, we consider that one-year follow-up could be insufficient for evaluating the potential clinical impact of MDR exacerbations and probably for that aim more subsequent exacerbations should be assessed.

\section{Limitations}

Pathogen identification relied mainly on conventional microbiological tests and invasive respiratory samples were only indicated if required by the attending physician; this is a real clinical scenario common in clinical hospital settings. No quantitative bacteriology measuring with colony counts was quantified in sputum. Due to the number of patients in the cohort, a secondary analysis to separate specific risk factors for each microorganism was not undertaken. Mild episodes of exacerbations treated in primary care and not evaluated in our specific clinics were not included.

\section{Strengths}

This is the first study aimed at identifying risk factors for MDR exacerbations with potential impact on clinical decisions for antibiotic choice. At present, BTS guidelines [28] suggest combination therapy rather than single-drug antibiotic therapy if a resistant strain of $P$ aeruginosa is isolated. Our findings could be useful for avoiding unnecessary broadspectrum antibiotics in patients without MDR risk factors.

\section{Conclusions}

Our findings have identified three independent risk factors hospitalization in the previous year, chronic renal disease, and prior multidrug-resistant isolation- for identification multidrug-resistant pathogens in $\mathrm{BE}$ exacerbations. This information may be useful for clinicians in guiding initial antibiotic therapy in exacerbations of BE. A further validation in different BE cohorts including distinct phenotypes and larger follow-up periods should be performed. MDR risk prediction in $\mathrm{BE}$ exacerbations is a new field that requires validation for clinical decision-making in selecting initial appropriate antibiotics and for safely avoiding anti-MDR coverage.

\footnotetext{
Abbreviations

AIDS: Acquired immunodeficiency syndrome; BE: Non-cystic fibrosis bronchiectasis; BSI: Bronchiectasis severity index; BTS: British Thoracic Society; CF: Cystic fibrosis; COPD: Chronic obstructive pulmonary disease;

ESBL: Extended-spectrum betalactamase; FACED: F (forced expiratory volume in $1 \mathrm{~s}$ [FEV1]); A (age; C: chronic colonization by Pseudomonas aeruginosa $[P A]) ; E$ (radiological extension [number of pulmonary lobes affected]); and D (dyspnea); HIV: Human immunodeficiency virus; MDR: Multidrug-resistant; MIC: Minimum inhibitory concentration; MRSA: Methicillin-resistant Staphylococcus aureus; PA: Pseudomonas aeruginosa; ROC: Receiver-operator characteristic
} 


\section{Acknowledgments}

The authors would like to thank Luz Mimbiela, Alexandra Gimeno and Alba Piró for their support, work and dedication to this project.

\section{Funding}

This work was supported by SEPAR 106/2012 and CIBERES (CB06/06/0028), CIBERES is an initiative of ISCIII.

\section{Availability of data and materials}

The datasets used and/or analysed during the current study are available from the corresponding author on reasonable request.

\section{Authors' contributions}

Study concept and design: RM, EP and AT. Acquisition of data: RMe, ER, LF, JS, SR, VA and IA. Analysis and interpretation of data: RM, RMe, ER, LF, JS, SR, VA and IA Drafting of the manuscript: RM. Critical revision of the manuscript for important intellectual content: RM, EP and AT. Statistical analysis: RM and RMe. RM, RMe, EP, $E R, L F, J S, S R, V A$, IA and AT read and approved the final manuscript.

\section{Authors' information}

Not applicable.

\section{Ethics approval and consent to participate}

Local committees approved the study and patients gave written informed consent (Biomedical research ethics committee Hospital La Fe 2011/0342).

\section{Consent for publication}

Not applicable.

\section{Competing interests}

Antoni Torres is a member of the editorial board (Associate Editor) of this journal.

\section{Publisher's Note}

Springer Nature remains neutral with regard to jurisdictional claims in published maps and institutional affiliations.

\section{Author details \\ ${ }^{1}$ Pneumology Department, Hospital Universitario y Politécnico La Fe / Instituto de Investigación Sanitaria (IIS) La Fe, Universidad de Valencia, Valencia, Spain. 2Fundació Clínic, Institut D' Investigacions Biomèdiques Agustí Pi i Sunyer (IDIBAPS), Barcelona, Spain. ${ }^{3}$ Microbiology Department, Hospital Universitario y Politécnico La Fe / Instituto de Investigación Sanitaria (IIS) La Fe, Valencia, Spain ${ }^{4}$ Pneumology Department, Hospital Clínico y Provincial, Universidad de Barcelona, Institut D' Investigacions Biomèdiques Agustí Pi i Sunyer (IDIBAPS), Barcelona, Spain. ${ }^{5}$ Centro de Investigación Biomédica En Red-Enfermedades Respiratorias (CIBERES, CB06/06/0028), Madrid, Spain.}

Received: 9 May 2017 Accepted: 21 September 2017

Published online: 30 September 2017

\section{References}

1. Chalmers JD, Aliberti S, Blasi F. Management of bronchiectasis in adults. Eur Respir J [Internet]. 2015 [cited 2015 Nov 17];45:1446-1462. Available from: http://www.ncbi.nlm.nih.gov/pubmed/25792635

2. Murray MP, Hill AT. Non-cystic fibrosis bronchiectasis. Clin Med. [Internet]. 2009 [cited 2015 Dec 30];9:164-169. Available from: http://www.ncbi.nlm. nih.gov/pubmed/19435127.

3. Aliberti S, Cilloniz C, Chalmers JD, Zanaboni AM, Cosentini R, Tarsia P, et al Multidrug-resistant pathogens in hospitalised patients coming from the community with pneumonia: a European perspective. Thorax [Internet] 2013 [cited 2014 Jan 5];68:997-999. Available from: http://www.ncbi.nlm.nih. gov/pubmed/23774884

4. Prina E, Ranzani OT, Polverino E, Cillóniz C, Ferrer M, Fernandez L, et al. Risk factors associated with potentially antibiotic-resistant pathogens in communityacquired pneumonia. Ann Am Thorac Soc. [Internet]. 2015 [cited 2015 Dec 3]; 12:153-160. Available from: http://www.ncbi.nlm.nih.gov/pubmed/25521229.

5. Vendrell M, de Gracia J, Olveira C, Martínez MA, Girón R, Máiz L, et al. [Diagnosis and treatment of bronchiectasis. Spanish Society of Pneumology and Thoracic Surgery]. Arch Bronconeumol. [Internet]. 2008 [cited 2015 Dec 30]:44:629-640. Available from: http://www.ncbi.nlm.nih.gov/pubmed/ 19007570
6. Charlson ME, Pompei P, Ales KL, MacKenzie CR. A new method of classifying prognostic comorbidity in longitudinal studies: development and validation. J Chronic Dis [Internet] 1987:40:373-383. Available from: http://www.ncbi. nlm.nih.gov/entrez/query.fcgi? $\mathrm{cmd}=$ Retrieve\&db=PubMed\&dopt= Citation\&list_uids $=3558716$

7. Chalmers JD, Goeminne P, Aliberti S, McDonnell MJ, Lonni S, Davidson J, et al. The bronchiectasis severity index. An international derivation and validation study. Am J Respir Crit Care Med. [Internet]. 2014 [cited 2015 Oct 21];189:576-585 Available from: http://www.pubmedcentral.nih.gov/ articlerender.fcgi?artid=3977711\&tool=pmcentrez\&rendertype=abstract

8. Martínez-García MÁ, de Gracia J, Vendrell Relat M, Girón R-M, Máiz Carro L, de la Rosa Carrillo D, et al. Multidimensional approach to non-cystic fibrosis bronchiectasis: the FACED score. Eur Respir J [Internet]. 2014 [cited 2015 Dec 28];43:1357-1367. Available from: http://www.ncbi.nlm.nih.gov/ pubmed/24232697.

9. Polverino E, Cilloniz C, Menendez R, Gabarrus A, Rosales-Mayor E, Alcaraz V, et al. Microbiology and outcomes of community acquired pneumonia in non cystic-fibrosis bronchiectasis patients. J Infect. [Internet]. 2015 [cited 2015 Dec 30];71:28-36. Available from: http://www.ncbi.nlm.nih.gov/ pubmed/25882347.

10. Magiorakos A-P, Srinivasan A, Carey RB, Carmeli Y, Falagas ME, Giske CG, et al. Multidrug-resistant, extensively drug-resistant and pandrug-resistant bacteria: an international expert proposal for interim standard definitions for acquired resistance. Clin Microbiol Infect. [Internet]. 2012 [cited 2014 Dec 11];18:268-281. Available from: http://www.ncbi.nlm.nih.gov/pubmed/ 21793988

11. Hosmer DW, Lemeshow S. Applied logistic regression. New York: John Wiley; 1989

12. Wilson R, Sethi S, Anzueto A, Miravitlles M. Antibiotics for treatment and prevention of exacerbations of chronic obstructive pulmonary disease. $J$ Infect [Internet]. 2013 [cited 2015 Dec 28];67:497-515. Available from: http:// www.ncbi.nlm.nih.gov/pubmed/23973659.

13. Sahuquillo-Arce J, Méndez R, Hernández-Cabezas A, Menéndez R. Non-cystic fibrosis bronchiectasis: The long road to multidrug resistant bacteria. Community Acquir Infect. [Internet]. 2016;3:110. Available from: http://www. caijournal.com/text.asp?2016/3/4/110/198491

14. Cetinkol Y, Yildirim AA, Telli M, Calgin MK. The investigation of oxacillinase/ metallo-beta-lactamase genes and clonal analysis in carbapenem-resistant Klebsiella pneumoniae. Infez Med Italy. 2016;24:48-53.

15. McDonnell MJ, Jary HR, Perry A, MacFarlane JG, Hester KLM, Small T, et al. Non cystic fibrosis bronchiectasis: A longitudinal retrospective observational cohort study of Pseudomonas persistence and resistance. Respir Med. [Internet]. 2015 [cited 2016 Feb 23];109:716-726. Available from: http:// www.ncbi.nlm.nih.gov/pubmed/25200914

16. Metersky ML, Frei CR, Mortensen EM. Predictors of Pseudomonas and methicillin-resistant Staphylococcus aureus in hospitalized patients with healthcare-associated pneumonia. Respirology [Internet]. 2016 [cited 2016 Mar 9];21:157-163. Available from: http://www.ncbi.n/m.nih.gov/pubmed/ 26682638

17. Izhakian S, Wasser WG, Fuks L, Vainshelboim B, Fox BD, Fruchter O, et al. Lobar distribution in non-cystic fibrosis bronchiectasis predicts bacteriologic pathogen treatment. Eur J Clin Microbiol Infect Dis. [Internet]. 2016 [cited 2016 Mar 13]; Available from: http://www.ncbi.nlm.nih.gov/pubmed/26873379.

18. Murray MP, Turnbull K, Macquarrie S, Hill AT. Assessing response to treatment of exacerbations of bronchiectasis in adults. Eur Respir J. [Internet]. 2009 [cited 2015 Nov 21];33:312-318. Available from: http://www. ncbi.nlm.nih.gov/pubmed/18829674.

19. Finklea JD, Khan G, Thomas S, Song J, Myers D, Arroliga AC. Predictors of mortality in hospitalized patients with acute exacerbation of bronchiectasis. Respir Med. [Internet]. 2010 [cited 2015 Dec 28];104:816-821. Available from: http://www.ncbi.nlm.nih.gov/pubmed/20363606

20. Shindo $Y$, Ito R, Kobayashi D, Ando M, Ichikawa M, Shiraki A, et al. Risk factors for drug-resistant pathogens in community-acquired and healthcareassociated pneumonia. Am J Respir Crit Care Med. [Internet]. 2013 [cited 2016 Jan 6];188:985-995. Available from: http://www.ncbi.nlm.nih.gov/ pubmed/23855620.

21. Shorr AF, Myers DE, Huang DB, Nathanson BH, Emons MF, Kollef MH. A risk score for identifying methicillin-resistant Staphylococcus aureus in patients presenting to the hospital with pneumonia. BMC Infect Dis. [Internet]. 2013 [cited 2016 Mar 16];13:268 Available from: http://www.pubmedcentral.nih. gov/articlerender.fcgi?artid=3681572\&tool=pmcentrez\&rendertype=abstract 
22. Calitri C, Scolfaro C, Colombo S, De Intinis G, Carraro F, Garazzino S, et al. Extended-Spectrum Beta Lactamase-producing Enterobacteriaceae among the pediatric population: who is at risk and why? Results from a singlecentre prospective study. Infez Med Italy. 2016:24:318-25.

23. Goeminne PC, Vandooren J, Moelants EA, Decraene A, Rabaey E, Pauwels A, et al. The Sputum Colour Chart as a predictor of lung inflammation, proteolysis and damage in non-cystic fibrosis bronchiectasis: a case-control analysis. Respirology [Internet]. 2014 [cited 2015 Dec 28];19:203-210. Available from: http://www.ncbi.nlm.nih.gov/pubmed/24286471.

24. Jung WJ, Kang YA, Park MS, Park SC, Leem AY, Kim EY, et al. Prediction of methicillin-resistant Staphylococcus aureus in patients with non-nosocomial pneumonia. BMC Infect Dis. [Internet]. 2013 [cited 2016 Mar 13];13:370 Available from: http://www.pubmedcentral.nih.gov/articlerender.fcgi?artid= 3751064\&tool=pmcentrez\&rendertype=abstract

25. Callejo-Torre F, Eiros Bouza JM, Olaechea Astigarraga P, Coma Del Corral MJ, Palomar Martinez M, Alvarez-Lerma F, et al. Risk factors for methicillinresistant Staphylococcus aureus colonisation or infection in intensive care units and their reliability for predicting MRSA on ICU admission. Infez Med Italy. 2016;24:201-9.

26. Gallego M, Pomares X, Espasa M, Castañer E, Solé M, Suárez D, et al. Pseudomonas aeruginosa isolates in severe chronic obstructive pulmonary disease: characterization and risk factors. BMC Pulm Med. [Internet]. 2014 [cited 2016 Mar 13];14:103 Available from: http://www.pubmedcentral.nih. gov/articlerender.fcgi?artid $=4094400 \&$ tool $=$ pmcentrez\&rendertype $=$ abstract

27. Cantón R, Fernández Olmos A, de la Pedrosa EGG, del Campo R, Antonia Meseguer M. [Chronic bronchial infection: the problem of Pseudomonas aeruginosa]. Arch Bronconeumol. [Internet]. 2011 [cited 2016 Mar 6];47 Suppl 6:8-13. Available from: http://www.ncbi.nlm.nih.gov/pubmed/ 21703473.

28. Pasteur MC, Bilton D, Hill AT. British Thoracic Society guideline for non-CF bronchiectasis. Thorax [Internet]. 2010 [cited 2016 Mar 1];65 Suppl 1:11-58. Available from: http://www.ncbi.nlm.nih.gov/pubmed/20627931.

29. Webb BJ, Jones B, Dean NC. Empiric antibiotic selection and risk prediction of drug-resistant pathogens in community-onset pneumonia. Curr Opin Infect Dis. [Internet]. 2016 [cited 2016 Mar 29];29:167-177. Available from: http://www.ncbi.nlm.nih.gov/pubmed/26886179.

30. Aliberti S, Lonni S, Dore S, McDonnell MJ, Goeminne PC, Dimakou K, et al. Clinical phenotypes in adult patients with bronchiectasis. Eur Respir J. [Internet]. 2016 [cited 2016 Mar 9]; Available from: http://www.ncbi.nIm.nih. gov/pubmed/26846833.

31. Lye DC, Earnest A, Ling ML, Lee T-E, Yong H-C, Fisher DA, et al. The impact of multidrug resistance in healthcare-associated and nosocomial Gramnegative bacteraemia on mortality and length of stay: cohort study. Clin Microbiol Infect. [Internet]. 2012 [cited 2016 Feb 23];18:502-508. Available from: http://www.ncbi.n/m.nih.gov/pubmed/21851482.

32. Martin-Loeches I, Torres A, Rinaudo M, Terraneo S, de Rosa F, Ramirez P, et al. Resistance patterns and outcomes in intensive care unit (ICU)-acquired pneumonia. Validation of European Centre for Disease Prevention and Control (ECDC) and the Centers for Disease Control and Prevention (CDC) classification of multidrug resistant organi. J Infect. [Internet]. 2015 [cited 2016 Jan 8];70:213-222. Available from: http://www.ncbi.nlm.nih.gov/ pubmed/25445887.

33. Goeminne PC, Scheers H, Decraene A, Seys S, Dupont LJ. Risk factors for morbidity and death in non-cystic fibrosis bronchiectasis: a retrospective cross-sectional analysis of CT diagnosed bronchiectatic patients. Respir Res. [Internet]. 2012 [cited 2015 Dec 28];13:21 Available from: http://www. pubmedcentral.nih.gov/articlerender.fcgi?artid=3379934\&tool= pmcentrez\&rendertype $=$ abstract

\section{Submit your next manuscript to BioMed Central and we will help you at every step:}

- We accept pre-submission inquiries

- Our selector tool helps you to find the most relevant journal

- We provide round the clock customer support

- Convenient online submission

- Thorough peer review

- Inclusion in PubMed and all major indexing services

- Maximum visibility for your research

Submit your manuscript at www.biomedcentral.com/submit
Ciomed Central 